\title{
EVALUATION OF MULTI-SKILLED LABOUR IN AN OFF-SITE CONSTRUCTION FACILITY USING COMPUTER SIMULATION HYBRID APPROACH
}

\author{
Beda Barkokebas ${ }^{1}$, Ryan Brown ${ }^{2}$, Mohammed Sadiq Altaf ${ }^{3}$, Farook Hamzeh ${ }^{4}$, Ahmed \\ Bouferguene $^{5}$ and Mohamed Al-Hussein ${ }^{6}$
}

\begin{abstract}
Off-site construction uses production lines to produce building components in a controlled factory setting. By shifting construction activities to an off-site environment, many manufacturing principles can be employed, including the use of simulation to predict production's performance and the impact of different labour arrangements. Typically, each workstation has a specialized labourer working only at the one station. Those workstations in the production line with the longest productive and wait times highly influence the throughput of the line. Often, some labourers are sitting idle while other stations are backlogged. Despite being successfully applied in offsite construction production lines, discrete event simulation fails to mimic construction task's accurately when submitted to the effect of multiskilled labourers floating through different workstations during work. This paper investigates a hybrid approach where discrete event and continuous simulation are combined in a hybrid approach to predict the impact of multi-skilled labour to reduce idle times and increase productivity by balancing cycle times. Take-off quantities from historical data are used as an input to the proposed hybrid model to determine the required duration and locations of multi-skilled labourers in the production line. Furthermore, the optimal number of multi-skilled labourers is found by balancing the costs of training multi-skilled labourers with facility overhead costs.
\end{abstract}

Keywords: Simulation, off-site construction, productivity, multi-skilling.

\section{INTRODUCTION}

Shifting construction to off-site facilities has become increasing popular due its productivity, quality, efficiency, and safety benefits (Modular Building Institute 2010). This is achieved by borrowing concepts and knowledge from the manufacturing industry (Zhang et al. 2016). Modular construction is a popular method of off-site construction in which building components are constructed into two dimensional panels, then the panels are assembled into a volumetric unit either in the factory or on-site.

Traditionally, project management assigns labourers with individual specializations to each workstation and the modules are built across the production line. Labourers do not migrate from their assigned stations, which results in bottlenecks at the workstations with the greatest work content, and in turn this has substantial impacts on the progress rate of

PhD Candidate, University of Alberta, Edmonton, Canada, barkokebas@ualberta.ca

MSc, University of Alberta, Edmonton, Canada, rabrown1@ualberta.ca

Technical Supervisor, ACQBUILT, Edmonton, Canada, sadiqa@acqbuilt.com

Associate Professor, University of Alberta, Edmonton, Canada, hamzeh@ualberta.ca

Professor, University of Alberta, Campus Saint-Jean, Edmonton, Canada, ahmedb@ualberta.ca

Professor, University of Alberta, Edmonton, Canada, malhussein@ualberta.ca 
projects (Arashpour et al. 2014). Moghadam (2014) identifies production levelling, scheduling, and production flow as key areas of focus to improve the manufacturing process. In each of these areas, the implementation of multi-skilled labour is suggested by using of a group of multi-skilled labourers to support stationary labourers and adjust takt times to better handle the variability of projects and allow for non-fixed activity durations. Wongwai and Malaikrisanachalee (2011) also argues that multi-skilled labour resources decrease project duration, increase job stability for workers, and allow for higher flexibility in task assignment.

Arashpour et al. (2014) analysed process integration strategies for the utilization of multi-skilled and found that borrowing labourers from underutilized workstations smooths the capacity imbalance in the overall production line. If the production process is found to have workstations with a high variability in production times, then indirect skill chaining (multi-skilled crews that operate over a limited zone of the production line) is the optimal solution. This group of multi-skilled labours is required to move into any station along the production line as needed. The upstream migration of multi-skilled personnel through the production line would balance labour requirements and reduced lead time of a module. The multi-skilled provides a flexible allocation of resources into the most complex stations (longest duration), which will allow for complex products to be produced at a similar pace as the simpler products.

Despite advantages in productivity, the impact to train labourers to be multi-skilled must be balanced with the production gains, as there is still a lack of quantitative evidence regarding the trade-off of this strategy (Nasirian et al., 2019). Moreover, Ahmadian et al. (2016) argues the possible salary increase for multi-skilled labourers hinders further adoption of this strategy. Hence, there is a clear need for a systematic method to address the use of multi-skilled labour in modular construction facilities. This paper proposes an experimental approach using simulation as a surrogate system to address the impact of multi-skilled labour in offsite construction manufacturing.

Computer simulation is an effective tool that can be used to evaluate scenarios such as the effect of multi-skilled labour in production. Discrete event simulation (DES) is used to evaluate production scenarios in a virtual environment prior to real production (Altaf et al., 2018). Studies have been published using simulation in modular construction manufacturing to assess various risk factors (Li et al. 2014) and system efficiency (Hammad et al. 2002). In both previous works, DES is effectively applied as task durations are determined by a series of factors of discrete nature and by discrete steps. However, this approach is not suitable to address events in which durations are affected continuously and are not changeable due to the start or finish of an occurrence such as multi-skilled labourers working in-and-out of workstations as demand is impacted by events simulated.

In this context, Antonelli et al. (2018) presents continuous simulation as an approach where systems and events are modelled based on feedback loops within itself thus being an effective manner to model events impacted by multi-skilled labourers. Despite the ability of continuous simulation to model events affected by feedbacks loops, Barlas and Özün (2018) points out that DES is better suited to model queueing systems due to the randomness of events based on stochastic distributions. Brito et al. (2011) indicates the combination of discrete event and continuous simulation, referred to as hybrid simulation, is potentially the optimal approach for problems when simulation requires both a low level of abstraction (e.g., predicting a start and end to a task based on randomness provided by DES) and a higher level of abstraction (e.g., a dynamic change to the production rate of an activity due to an increase or decrease of resources). 
Barkokebas et al. (2015) evaluated the effect of incorporating dynamic workstations (workstations comprised of multi-skilled labourers) for the floor and wall production lines in an off-site construction facility. The study used discrete event simulation (DES) and continuous simulation to prove that multi-skilled labour balanced fluctuations in workflow and improved overall production without increasing the number of labourers. While multiskilled labour was found to shorten production time, questions remain with respect to the added cost of hiring and training highly skilled labourers. Hence, this study still lacks information regarding the financial impact of the use of multi-skilled labour in the production line. In fact, the financial impact is addressed as a multi-dimensional problem in which there is a significant investment and still no clear trade-off between investment and benefits in this solution. Moreover, other aspects are also important to address such as space constraints; each station is limited by the amount of space available, which limits the number of workers performing simultaneously at a given time.

This paper aims to address the features of both DES and continuous simulation to better model the impact of multi-skilled labour in offsite construction manufacturing. The objective is to determine the optimal number of multi-skilled labourers in the facility and quantify the line balancing, lead time, and productivity benefits from the introduction of the multi-skilled labourer(s). Based on material data gathered from Moghadam (2014) at an offsite construction facility, and the results generated from discrete and continuous (hybrid) simulation, multi-skilled labour will be evaluated on a cost-benefits basis.

\section{METHODS}

The methods applied in this research are presented in this section and summarized in Figure 1 below. The plant layout containing the number of stations and its precedence is modelled along with the respective number of resources (i.e. fixed labour) for each. Manhour requirements are added in the model through a labour database that calculates the labour requirements dependent upon project's attributes such as size, number of elements, etc. Hourly cost for direct (fixed and multi-skilled labour) and indirect (factory overhead such as utilities, space rental, etc.) labour are added in the model so a financial assessment can be performed. A comparison between the current and potential improvements in time and cost are important criterion to determine a good trade-off for the use of multi-skilled labour in the production line while space constraints (e.g. maximum number of labourers that can fit in a station) help determine the feasibility of each scenario. The shift length determines how often multi-skilled labourers are allowed to move between stations and how long they will work in there. Moreover, the research is based on two assumptions: (1) the productivity of fixed and multi-skilled labour is the same, and (2) there is no space constraint between stations (i.e. stations will not stop work due to queue length ahead). 


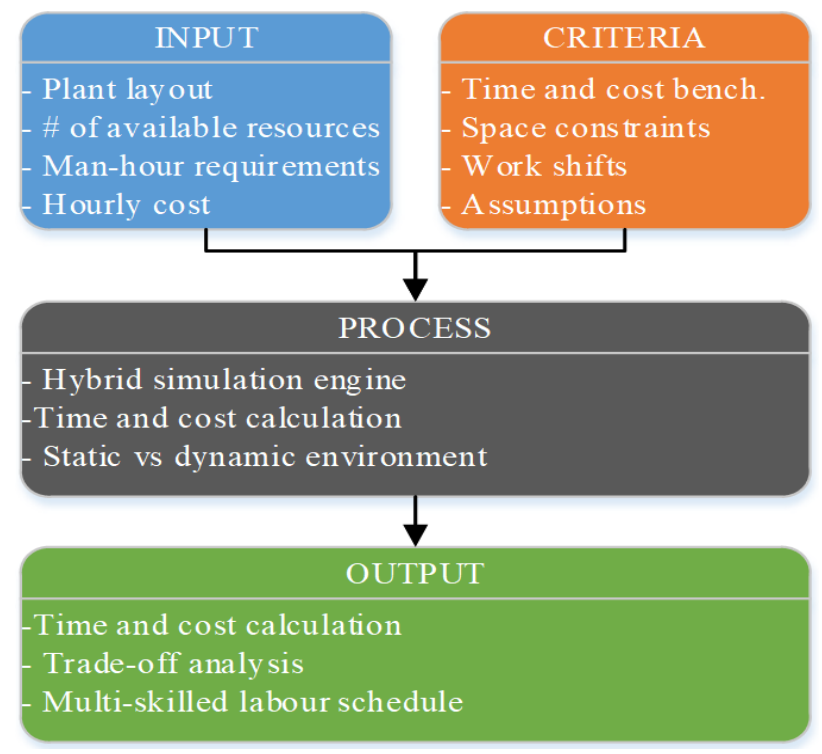

Figure 1: Methods overview

With all this information at hand, man-hour requirements for each project are added to the simulation engine, which consists of a combined discrete and continuous environments (hybrid). As per the given layout, projects are modelled as entities in a discrete environment while fixed (workers which won't leave their stations) and multi-skilled labourers are also modelled as discrete resources. The interaction between both environments for any simulated task is demonstrated in Figure 2 in which the database containing the man-hour requirements for each simulated task is connected to the simulation model developed in Simphony.NET and triggered at the discrete environment. After started, the number of fixed labourers and man-hour requirements for the task are sent to the continuous simulation environment which initiates an interaction with the multi-skilled resource pool at the discrete environment. Through each work shift, the task is performed at the continuous environment which requests multi-skilled labourers from the modelled pool at the DES environment, assigns these labourers as per Equation 1 and sends them to the continuous environment where the production rate is calculated as per Equation 2. Task man-hour requirements are deducted from the calculated production rate at each shift until it reaches to zero (i.e. end of task) and its final duration is calculated as per Equation 3 and added to the database. 


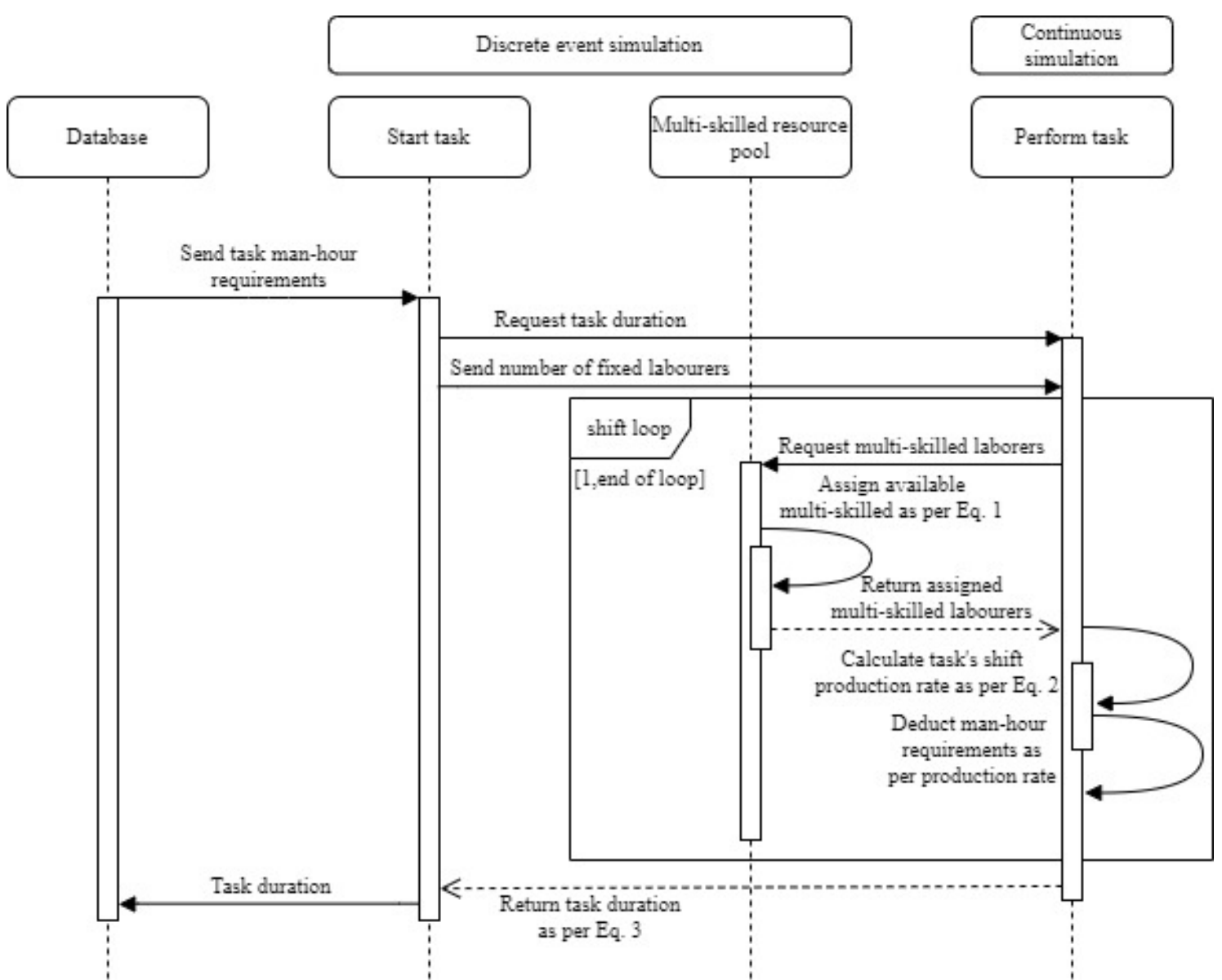

Figure 2: Sequence diagram between discrete event and continuous environments for a simulated task

$$
\begin{gathered}
\text { Station }_{i}=\operatorname{Max}\left(\frac{M h r_{i}^{1}}{P_{i}^{1}}+\cdots+\frac{M h r_{i}^{n}}{P_{i}^{n}}\right) \\
P_{i}^{n}=f_{i}^{n}+m_{i}^{n} \\
\text { Duration }^{n}=\sum_{1}^{i} \frac{M h r_{i}^{n}}{P_{i}^{n}}
\end{gathered}
$$

where:

Station $_{i}$ : Station where the multi-skilled labourer will work at shift i

$M h r_{i}^{\mathrm{n}}$ : Task man-hour requirement of station $\mathrm{n}$ at shift $\mathrm{i}$

$P_{i}^{n}$ : Production rate at station $\mathrm{n}$ at shift $\mathrm{i}$

$f_{i}^{n}$ : Fixed labour at station $\mathrm{n}$ at shift $\mathrm{i}$

$m_{i}^{n}$ : Assigned multi-skilled labour at station $\mathrm{n}$ at shift $\mathrm{i}$

Duration $^{n}$ : Total duration of station $\mathrm{n}$

As per Equation 1, the multi-skilled labourer is assigned to the station with the highest amount of man-hours left taking in consideration the production rate at each station as per Equation 2 representing the labour assigned (fixed and multi-skilled) at the given time assuming fixed and multi-skilled labour have the same productivity. In order to make scheduling of multi-skilled labour a realistic effort for modular contractors, Equation 1 is applied to each available multi-skilled labourer at the beginning the production line's shift 
(i.e., where each multi-skilled labourer should work for the given shift). Moreover, the logic for the allocation of multi-skilled labour is also dependent of the context provided in the given layout, such as space constraints, and which stations should allow for the use of multi-skilled labour as will be discussed in the next section. After the task is performed, total duration is calculated as per Equation 3 and the project (simulated entity) moves to the next station.

The total cost is calculated as per Equations 4, 5 and 6 below taking in consideration the direct and indirect costs incurred from the use of multi-skilled labour in the production line. Due to its extra training and expertise, it is assumed multi-skilled labour has a higher hourly rate paid by the employer. As observed in the equations below, the total cost consists of the sum of direct and indirect cost, which is represented by the product of manhours spent by fixed and multi-skilled and its unit rates and factory's overhead represented by the product of total production time and factory's hourly overhead rate.

$$
\begin{gathered}
\text { Total Cost = Direct Cost }+ \text { Indirect Cost } \\
\text { Direct Cost }=M H r_{f} \times \$_{f}+M H r_{m} \times \$_{m} \\
\text { Indirect Cost }=T_{m} \times \$_{i}
\end{gathered}
$$

where:

Total Cost: Total cost in production line

Direct Cost: Cost incurred from labour in all stations

Indirect Cost: Cost incurred from overhead and fixed cost from the factory

$M H r_{f}$ : Total man-hours worked by fixed labour in all stations

$\$_{f}$ : Hourly rate for fixed labour

$M H r_{m}$ : Total man-hours worked by multi-skilled labour in all stations

$\$_{m}$ : Hourly rate for multi-skilled labour

$T_{m}$ : Total simulation time

$\$_{i}$ : Hourly rate for factory's overhead

By collecting station times and total cost, different scenarios are calculated by changing the number of available multi-skilled labourers in the simulated environment starting from a static (no multi-skilled labour) and moving to a dynamic (use of multi-skilled labour) environment. After simulation is performed, the results are analysed as a trade-off between the overall cost and time spent to manufacture all simulated projects. After selecting the best scenario, a schedule is provided for each multi-skilled labourer indicating which station he should be at during each worked shift. The presented methods will be better described in the next section through a case study.

\section{CASE STUDY}

The case study consists of a wood-frame modular facility in Edmonton, Alberta, Canada with labour intensive operations that rely on a few cranes and traditional construction equipment. The introduction of multi-skilled labour can represent a significant improvement in production lines such as this in which workers are the main driver of 
production. Figure 3 demonstrates the addressed layout in this paper with its stations and respective fixed resources.

The first identified bottleneck in the addressed layout is Station 2 since, in order to begin, both Stations 1a and $1 \mathrm{~b}$ need to be completed (i.e., if one finishes before the other, it will remain idle while Station 2 will also be waiting for work commencement). The other identified bottleneck is in Station 3 due to idleness in the preceding Stations 1c and 2 when one finishes before the other, which potentially affects the remaining production. Hence, this research will evaluate the impact of multi-skilled labourers at the wall, floor, and roof framing stations (1a, 1b and 1c, respectively), which are considered the bottlenecks of the production line as highlighted in Figure 3 below.

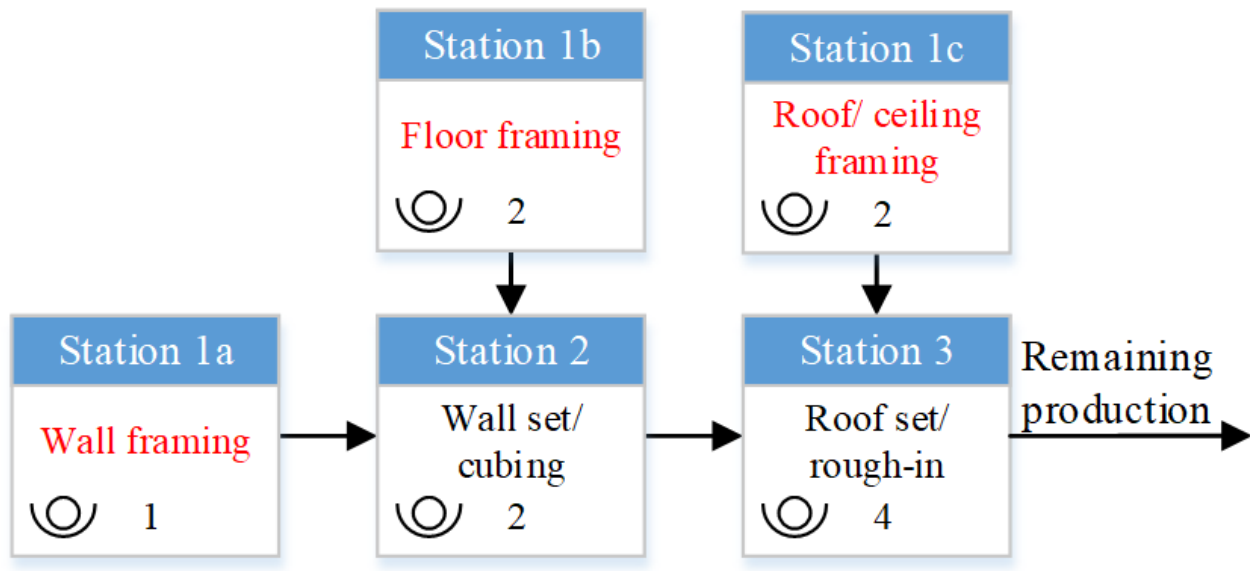

Figure 3: Addressed layout in the case study

The simulation model is first run with a scenario in which no multi-skilled labours are used (static scenario) in order to determine the current state of the production facility as a benchmark cost and timewise. After the benchmark is established, the simulation is rerun under different (dynamic) scenarios in which fixed labour is substituted by multiskilled labour (i.e. Station 1c will be given one fixed and multi-skilled labour) and multiskilled labourers are added in the production line. Based on the given layout and resources allocated, the logic for allocation of multi-skilled labour is demonstrated in Figure 4 below.

As demonstrated in Figure 4, the roof station is given preference for the use of multiskilled labour if the walls and floors of the project are already finished. If that is not the case, the work to be performed in the addressed stations (wall, floor and roof stations) are compared and the multi-skilled labourer will help the station that satisfies Equation 1 at the given time. This analysis is simulated for every multi-skilled labourer at the end of each shift. In this particular facility, workers work a total of 8 hours a day divided into 4hour shifts.

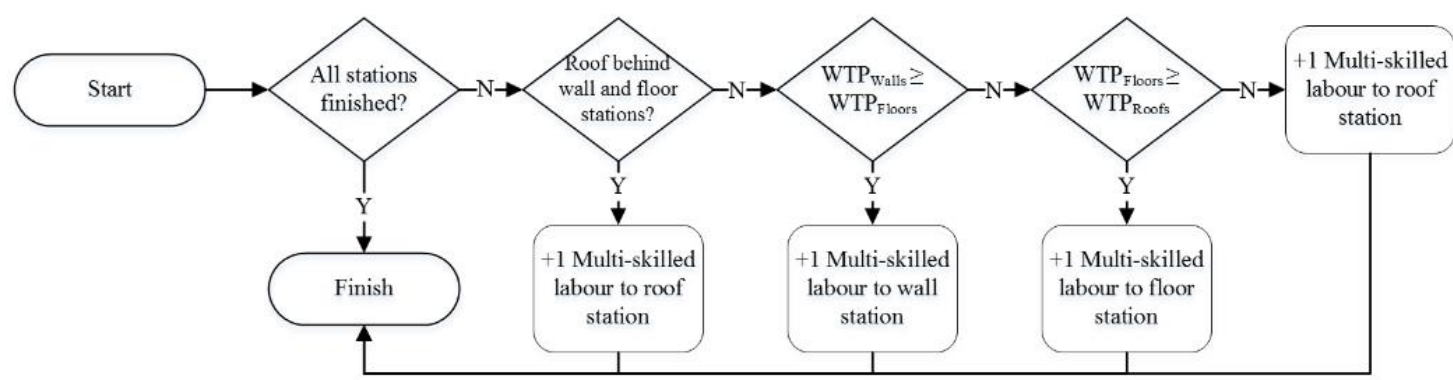

Figure 4: Proposed logic for multi-skilled labour 
Man-hour requirements for each station and project are added in the simulation model from a labour database containing time studies performed as per statistical analysis in the case study manufacturing facility by Moghadam (2013). The projects, and their man-hour requirements for each station are described in Table 1 below, which consists of a combination of residential, commercial, and office spaces built using wood-frame structural members. The order in which these projects will be manufactured, and their impact in balancing the production, will not be addressed in this research as this decision is not taken by the production team but rather based on commercial and client deadline requirements.

Table 1: Projects addressed in case study

\begin{tabular}{lllllll}
\hline \multirow{2}{*}{ ID } & Total & \multicolumn{7}{l}{ Total man-hours per station } \\
& Area $(\mathrm{m} 2)$ & $1 \mathrm{a}$ & $1 \mathrm{~b}$ & $1 \mathrm{c}$ & 2 & 3 \\
\hline $420 \mathrm{~A}$ & 65.59 & 18 & 17 & 16 & 18 & 20 \\
$420 \mathrm{~B}$ & 64.85 & 16 & 16 & 18 & 16 & 20 \\
432 & 147.16 & 24 & 22 & 46 & 32 & 32 \\
433 & 122.63 & 21 & 18 & 32 & 31 & 28 \\
434 & 147.16 & 22 & 20 & 54 & 30 & 32 \\
$442 \mathrm{~A}$ & 61.78 & 10 & 14 & 13 & 12 & 16 \\
$442 \mathrm{~B}$ & 61.78 & 12 & 14 & 14 & 16 & 12 \\
$443 \mathrm{~A}$ & 61.78 & 7 & 14 & 12 & 12 & 12 \\
$443 \mathrm{~B}$ & 61.78 & 11 & 12 & 15 & 15 & 12 \\
$431 \mathrm{~A}$ & 61.32 & 12 & 14 & 12 & 12 & 12 \\
$431 \mathrm{~B}$ & 56.58 & 14 & 11 & 26 & 11 & 12 \\
\hline SUM & 912.41 & 167 & 172 & 258 & 205 & 208 \\
\hline
\end{tabular}

As observed in Table 1, a total of 11 modules from 7 different projects (e.g., project 420 consists of modules A and B) are addressed in the simulation model. A big discrepancy can be observed between the man-hour requirements of different modules due the high variability of projects attributes (number of openings, walls, etc.) thus producing an unbalanced production line with significant idle time between stations. In order to develop a stochastic model, the upper and lower ranges using a 95\% confidence interval were estimated by applying student's t-distribution. With these ranges and information in Table 1 , the duration of tasks is modelled as triangular distributions and the simulation is run one thousand times, so its averages are collected and analysed.

Moreover, additional input data such as the hourly cost for fixed labour, multi-skilled labour, factory overhead, and the maximum number of workers allowed to work at the stations are displayed in Table 2. Since no multi-skilled labour is currently used on the production line, there is no evidence of its actual cost. Hence, the multi-skilled labour rate is assumed to be the same initially and, in subsequent simulations, possible additional labour costs (e.g., extra training, expertise, etc.) are addressed in increments of $20 \%$ to the hourly rate until it reaches double the fixed labour cost (i.e., \$50/ hr). Factory overhead cost includes all stations depicted in Table 2 while the maximum number of workers to work in the multi-skilled stations is 7 due space constraints (i.e., not enough space for more workers to work in these stations). The results of the analysis are presented in the next section. 
Evaluation of multi-skilled labour in an off-site construction facility using computer simulation hybrid approach

Table 2: Input data used in case study

\begin{tabular}{ll}
\hline Cost for fixed labour & $\$ 25 / \mathrm{hr}$ \\
Base cost for multi-skilled labour & $\$ 25 / \mathrm{hr}$ \\
Increments for multi-skilled labour & Base cost $+20 \%$ \\
Factory overhead & $\$ 750 / \mathrm{hr}$ \\
Max number of workers allowed & 7 workers \\
\hline
\end{tabular}

\section{MODEL VALIDATION \& RESULTS}

This section presents the results of the case study while providing insightful information regarding the impact of multi-skilled labour given the current factory layout. Initially, the simulation will run with the current factory state in which no multi-skilled labour is used. Results are then compared for model validation and alternative scenarios with the use of multi-skilled labour are simulated for further analysis. Finally, a scenario will be selected for further detailing and a schedule for multi-skilled workers will be developed based on simulation results.

For the validation process, the developed model simulated the production line under the same conditions as the model used by Moghadam (2013) to validate the productivity of the modular facility being studied. In this previous work, a simulation model was developed to validate the current production time (without multi-skilled labour) through comparing the model and actual production. The results of the developed model are compared with the previously validated model by the company and the results are 167.27 and 167 man-hours, respectively, with an error of less than $1 \%$. Therefore, the developed model is validated through a comparison with previously validated models and actual results.

For the presentation of scenarios, the terminology for scenario names is SC 5-0 where the first and second number represent the number of fixed and multi-skilled labour used in the scenario, respectively. By adding multi-skilled workers and also using them to replace fixed labour, scenarios are developed respecting the maximum number of workers allowed in the stations as Figure 5 demonstrates the total time and cost of alternative scenarios against the current state (SC 5-0). As per Figure 5, all scenarios indicate reduction in both time and cost when using multi-skilled labour in the modular construction facility. 


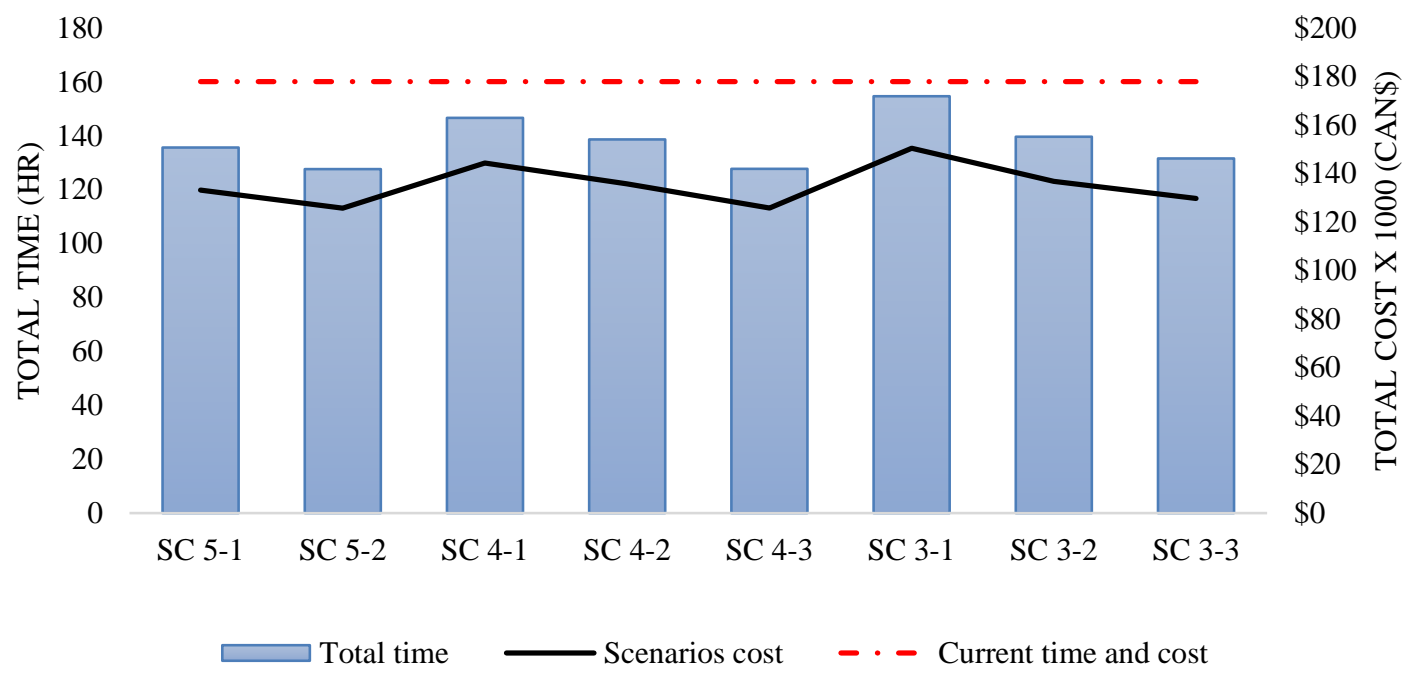

Figure 5: Total time and cost for addressed scenarios

Figure 5 demonstrates time and cost reduction through two strategies: (1) the use of multiskilled labour in which no extra workers are added to the production line (SC 4-1,3-1 and $3-2$ ) and (2) the addition of multi-skilled labour to the existing production line with the remainder of scenarios. Scenario 3-2 provides the best results when taking in consideration the impact of multi-skilled labour alone with a potential time and cost reduction of $21 \%$ and 23\% respectively. These results indicate the impact of application of multi-skilled labour to balance the production despite its variability while introducing a new culture in the production line altogether.

However, the increase in the number of workers (fixed and multi-skilled) in the scenarios presents the lowest cost, which indicates that indirect cost (i.e., facility amenities, rental, administration, etc.) is a significant portion of overall cost. The lowest total time and cost are found in scenarios SC 5-2 and SC 4-3 where 2 additional multi-skilled workers are hired, and an extra multi-skilled worker could be trained from the original staff or could be a new hire as well.

In both cases, it is clear the initial stations in Figure 5 (1a,1b and 1c) are understaffed and, by following any of the presented strategies, more workers should be employed there. Moreover, the results indicate a shift in the production line's bottleneck from the Stations $1 \mathrm{a}, 1 \mathrm{~b}$ and $1 \mathrm{c}$ to Stations 2 and 3 in which further simulation should be applied to balance the production line as a whole. In order to do that more stations downstream should be modelled while identifying possible multi-skilled labour to be applied.

Furthermore, there is no clear evidence of the impact of an hourly rate increase, which is the premium for multi-skilled work; therefore, a more detailed analysis is required to better understand the true impact of multi-skilled labour on the overall cost of the production in the modular construction facility. Figure 6 demonstrates a sensitivity analysis of the scenarios with their respective number of fixed workers in each station, multi-skilled labour, total time, and the cost difference from the current baseline, which is SC 5-0 (5 fixed labourers only) as per Figure 6 and Equations 4, 5 and 6. 


\begin{tabular}{|c|c|c|c|c|c|c|c|c|c|c|c|}
\hline \multirow[t]{2}{*}{$\mathrm{SC} \#$} & \multicolumn{3}{|c|}{$\begin{array}{l}\text { Fixed } \\
\text { labour }\end{array}$} & \multirow{2}{*}{$\begin{array}{c}\text { MS } \\
\text { Labour }\end{array}$} & \multirow{2}{*}{$\begin{array}{l}\text { Total } \\
\text { Time } \\
\text { (hr) }\end{array}$} & \multicolumn{6}{|c|}{$\begin{array}{l}\text { Cost difference \& rate increment for } \\
\text { multi-skilled labour }\end{array}$} \\
\hline & $1 \mathrm{a}$ & $1 b$ & $1 \mathrm{c}$ & & & $+0 \%$ & $+20 \%$ & $+40 \%$ & $+60 \%$ & +80 & $+100 \%$ \\
\hline $5-0$ & 1 & 2 & 2 & & & & & & & & $0 \%$ \\
\hline & 1 & 2 & 2 & & & $-25 \%$ & $-25 \%$ & & & & -24 \\
\hline & 1 & 2 & 2 & & & $-29 \%$ & $-29 \%$ & & & & $-27 \%$ \\
\hline & 1 & 1 & 2 & & & $-19 \%$ & $-19 \%$ & & & & -179 \\
\hline $4-2$ & 1 & 1 & 2 & & & $-24 \%$ & $-23 \%$ & & $2 \%$ & & $-21 \%$ \\
\hline SC $4-3$ & 1 & 1 & 2 & & & $-29 \%$ & $-29 \%$ & $-28 \%$ & $-27 \%$ & $-26 \%$ & $-26 \%$ \\
\hline SC $3-1$ & 1 & 1 & 1 & & & $-15 \%$ & $-15 \%$ & $15 \%$ & $-14 \%$ & $-14 \%$ & 120 \\
\hline SC $3-2$ & 1 & 1 & 1 & & & $-23 \%$ & $-22 \%$ & & $-21 \%$ & $-21 \%$ & $-20 \%$ \\
\hline C 3-3 & 1 & 1 & 1 & & & $-27 \%$ & $-26 \%$ & $-25 \%$ & $-25 \%$ & $-24 \%$ & $-23 \%$ \\
\hline
\end{tabular}

Figure 6: Sensitivity analysis of the scenarios

Figure 6 confirms the better results of scenarios SC 5-2 and SC 4-3 with a cost reduction of $29 \%$ for each, while indicating that premiums on multi-skilled labour do not contribute significantly to the overall cost in the production line: there is only a $3 \%$ increase in the total cost when multi-skilled labourers earn twice as much as fixed labour workers. However, it is important to note the developed simulation addresses the production at its natural state and it does not simulate the impact of these changes during implementation stages. Hence, it is reasonable to forecast an additional cost due to the implementation of changes and adaptation of workers to new environment and workflow. Moreover, both scenarios indicate a reduction of $29 \%$ in comparison to the current production time (SC 50 ), the scenario against which all comparisons are being performed. Another remaining question is the impact of direct and indirect cost when addressing the use of multi-skilled labour in modular construction facilities. In order to do that, a scenario will be chosen for further analysis.

Although results from both scenarios SC 5-2 and SC 4-3 are similar, the first scenario of those scenarios is chosen for further analysis since it provides less change in the current state of the production line (i.e., re-training currently employed labourers wouldn't be necessary, which means the modular contractor can hire 2 additional multi-skilled workers). Figure 7 shows the cost breakdown between direct and indirect costs represented by the work in stations and factory overhead, respectively, while the chart on the right describes the cost contribution between fixed and multi-skilled labour for the stations being considered in this case study. 


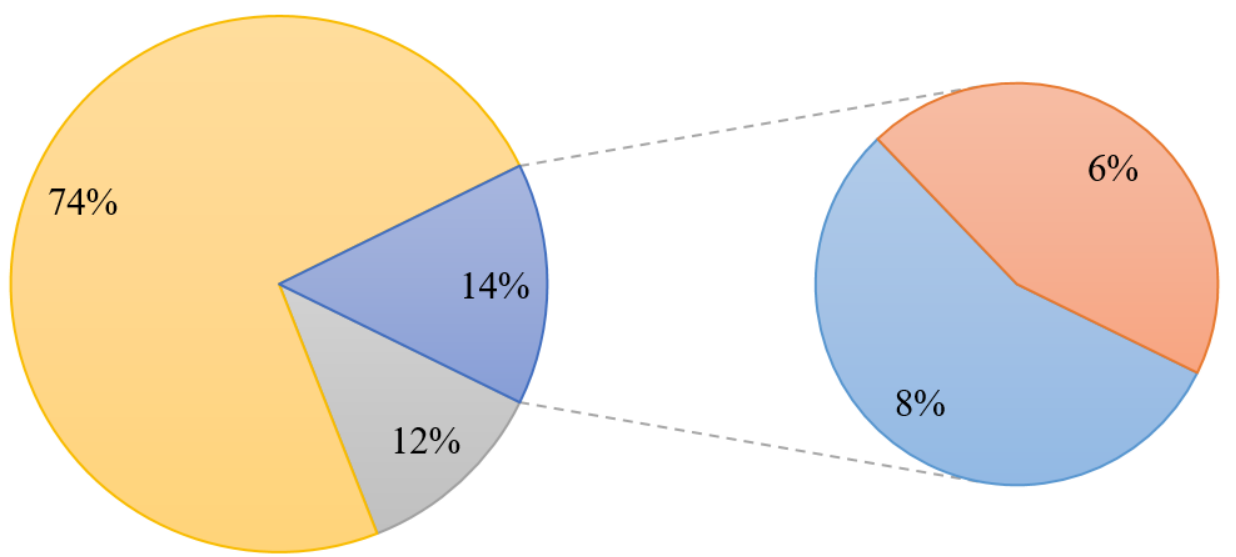

$\square$ Stations 1a,b\&c: Fixed Labor

$\square$ Stations $2 \& 3$ $\square$ Stations 1a,b\&c: MS Labor

$\square$ Indirect Cost

Figure 7: Cost breakdown of Scenario 5-2

As shown in Figure 7, the less favourable scenario in which multi-skilled labourers are paid twice as much as fixed labourers is taken into consideration in order to provide the modular contractor a broader insight into the difficulties of involving multi-skilled labour in its production line. From the graph, it is clear the indirect cost is the highest contributor, representing almost two thirds of the overall production cost. Even considering the worst case, in which the hourly rate premium for multi-skilled labour is at the highest amount considered in this study, the use of multi-skilled labour only impacted the overall cost by $6 \%$, where, when the multi-skilled rate is the same as the rate for fixed labour, the impact is reduced to as low as $3 \%$.

Considering the cost reduction of $29 \%$ between the current production cost and the evaluated scenario (SC 5-0 and SC 5-2, respectively), it is safe to recommend the use of multi-skilled labour in the modular construction facility. Moreover, Figure 7 indicates that in order to significantly reduce the overall cost, future improvement should be focused on reducing overall production time in order to minimize indirect cost that represents the factory's overhead (functioning hourly cost). To finalize the proposed work, a schedule for the proposed multi-skilled labour suggested in SC 5-2 is developed based on simulation results and the needs for multi-skilled workers at the stations as per Equation 1.

Figure 8 shows the schedule for SC 5-2 in which two multi-skilled labourers assist the respective stations in the plant for each 4-hour shift needed to complete the 11 simulated modules. This schedule was developed assuming 5 fixed labourers and assuming that the multi-skilled labourers are able to work freely between the floor, wall and roof stations. The schedule highlights the need for dynamic labour to balance the production lines. As variability in projects is encountered, the production rate of the lines shifts to accommodate this.

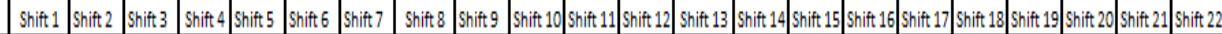

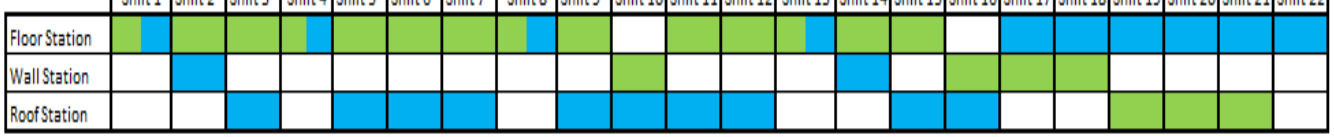

Figure 8: Proposed multi-skilled labour schedule for Scenario 5-2 
Evaluation of multi-skilled labour in an off-site construction facility using computer simulation hybrid approach

\section{CONCLUSIONS}

The research intends to explore the interactions between discrete and continuous simulation thus proposing a hybrid approach to address the impact of multi-skilled worker in modular construction facilities using simulation while addressing the context of each production line and its limitations. Through the development and validation of a hybrid simulation, several scenarios were developed taking into consideration the maximum number of workers allowed due to space constraints, direct cost, multi-skilled work premiums and indirect cost such as factory's overhead. The hybrid approach is demonstrated to be effective in simulating the variable duration of construction task as per the availability of multi-skilled labourers through work shifts and overall production's balance.

Moreover, 11 modules from 7 different projects were simulated taking into consideration each module's attributes and variability. According to simulation results, the impact of multi-skilled labour is positively confirmed with a time and cost potential reduction of 21 and $23 \%$, respectively while not adding extra labour to the production line and relying on the levelling of resources entirely.

However, and despite what many people often assume, the addition of more workers contributes to a decrease in the overall cost and production time. It was shown here that adding 2 multi-skilled workers to work in 3 different stations as per required at the end of each work shift reduces the total production time by $29 \%$ when compared with the current production time, which uses 5 fixed labourers who only work at their respective stations.

Moreover, it is concluded that by adding 2 multi-skilled workers to the production line the overall cost is reduced by $29 \%$, while the cost attributable to multi-skilled labour only represents $6 \%$ of the total. In fact, the main contributor for the overall cost is the indirect cost, which is responsible for almost $75 \%$ of the total thus suggesting the modular contractor develop other solutions to reduce total production time and cost.

After the trade-off analysis is performed and suitable scenarios are selected, a schedule for the multi-skilled labourers is developed in order to provide better scheduling for floor managers regarding where to allocate labour resources. The information from the schedule is extracted from the simulation model and later modified to fit the manager's preference following the shift's duration at the modular facility.

Finally, in order to identify the impact of multi-skilled labour in a general problem, this research suggests the following steps to evaluate the impact of multi-skilled labour in operations:

1. Observe the process in question,

2. Analyse the process using metrics at hand (e.g. time, cost, etc.),

3. Identify which work (in this case, stations) in the process can be improved by the use of multi-skilled labour,

4. Simulate the current and proposed scenarios,

5. Analyse the different scenarios as per metrics used in Step 2.

Although this study provides interesting insights in regards to the use of multi-skilled labour in modular construction facilities, the simulation model still has certain assumptions limiting its capacity such as: (1) adequate space to store idle panels between stations, (2) fixed and multi-skilled labourers have the same productivity rates. Moreover, this work does not consider the implementation and adaptation process of introducing the multi-skilled labour in the production line, nor integrated new projects attributes in a systematic manner for further analysis. A hybrid approach is further considered to 
simulate other aspects of production such as the learning effect on multi-skilled labourers and employee turnover. Hence, the authors intent to explore and address these assumptions in future research.

\section{ACKNOWLEDGEMENTS}

The authors would like to acknowledge everyone at the case study company for their contributions, hard work, and for allowing us to observe their actions at the facility in order to collect the data needed for this study. We would like to specifically thank Mansooreh (Mana) Moghadam for her invaluable collaboration in this work.

\section{REFERENCES}

AbouRizk, S., and Mohamed, Y. 2000. Simphony-an integrated environment for construction simulation. 2000 Winter Simulation Conference Proceedings (Cat. No.00CH37165), 2, 1907-1914.

Ahmadian Fard Fini, A., T. H. Rashidi, A. Akbarnezhad, and S. T. Waller. 2016. Incorporating multiskilling and learning in the optimization of crew composition. Journal of Construction Engineering Management, 142 (5): 04015106. doi.org/10.1061/(ASCE)CO.1943-7862.0001085

Antonelli, D., Litwin, P., Stadnicka, D. Multiple systems Dynamics and Discrete Event Simulation for manufacturing system performance evaluation. 2018. Procedia CRIP, Vol. 78, pp. 178-183. https://doi.org/10.1016/j.procir.2018.08.312.

Arashpour, M., Wakefield, R., Blismas, N., and Minas, J. 2014. Optimization of process integration and multi-skilled resource utilization in off-site construction. Automation in Construction, Vol. 50, pp. 72-80.

Barkokebas, B., Bu Hamdan, S., Alwisy, A. and Al-Hussein M. 2015. Evaluation of the Impact of Dynamic Work Stations Versus Static Work Stations in Wood Framing Prefabrication Using Hybrid Simulation. Proceedings of Modular and Off-site Construction. May 19-21, Edmonton, Alberta, Canada.

Moghadam, M. 2014. Lean-Mod: An Approach to Modular Construction Manufacturing Production Efficiency Improvement. Ph. D., University of Alberta.

Altaf, M. S., Bouferguene, A., Liu, H., Al-Hussein, M., and Yu H. 2018. Integrated production planning and control system for a panelized home prefabrication facility using simulation and RFID. Automation in Construction, vol. 85, pp. 369-383.

Li, H. X., Al-Hussein, M., Lei, Z., and Ajweh, Z. 2013. Risk identification and assessment of modular construction utilizing fuzzy analytic hierarchy process (AHP) and simulation. Canadian Journal of Civil Engineering, 40(12), 1184-1195.

Modular Building Institute. 2010. Improving Construction Efficiency \& Productivity with Modular Construction. The Modular Building Institute, pp.1-16.

Nasirian, Araz, Mehrdad Arashpour, and Babak Abbasi. 2019. Critical Literature Review of Labor Multiskilling in Construction. Journal of Construction Engineering and Management 145 (1): 04018113. https://doi.org/10.1061/(ASCE)CO.1943-7862.0001577.

Wongwai, N., Malaikrisanachalee, S. 2011. Augmented heuristic algorithm for multiskilled resource scheduling. Automation in Construction, 20, 429-445.

Yaman Barlas \& Onur Özgün (2018) Queuing systems in a feedback environment: Continuous versus discrete-event simulation, Journal of Simulation, 12:2, 144-161, DOI: $10.1080 / 17477778.2018 .1465153$ 
Zhang, Y., Fan, G., Lei, Z., Han, S., Raimondi, C., Al-Hussein, M., Bouferguene, A. 2016. Lean-based diagnosis and improvement for off-site construction factory manufacturing facilities. ISARC Proc., 33, Vilnius Gediminas Technical University, Department of Construction Economics \& Property, 1090-1098. 